SUBJECT AREAS:

ENVIRONMENTAL

CHEMISTRY

CIVIL ENGINEERING

Received

18 June 2014

Accepted

9 September 2014

Published

1 October 2014

Correspondence and requests for materials should be addressed to

J.H.Q. (jhqu@rcees. ac.cn)

\title{
Pre-treatment for ultrafiltration: effect of pre-chlorination on membrane fouling
}

\author{
Wenzheng $Y u^{1,2}$, Lei $X u^{1}$, Nigel Graham² \& Jiuhui $Q u^{1}$
}

\begin{abstract}
${ }^{1}$ Key Laboratory of Drinking Water Science and Technology, Research Center for Eco-Environmental Sciences, Chinese Academy of Sciences, Beijing 100085, China, ${ }^{2}$ Department of Civil and Environmental Engineering, Imperial College London, South Kensington Campus, London SW7 2AZ, UK.
\end{abstract}

Microbial effects are believed to be a major contributor to membrane fouling in drinking water treatment. Sodium hypochlorite $(\mathrm{NaClO})$ is commonly applied in membrane cleaning, but its potential use as a pretreatment for controlling operational fouling has received little attention. In this study, the effect of adding a continuous low dose of $\mathrm{NaClO}(1 \mathrm{mg} / \mathrm{l}$ as active $\mathrm{Cl})$ in combination with alum, before ultrafiltration, was compared with only alum as pretreatment. The results showed that the addition of $\mathrm{NaClO}$ substantially reduced membrane fouling both in terms of the rate of TMP development and the properties of the membrane cake layer. Although the size of nano-scale primary coagulant flocs changed little by the addition of $\mathrm{NaClO}$, the cake layer on the membrane had a greater porosity and a substantially reduced thickness. $\mathrm{NaClO}$ was found to inactivate bacteria in the influent flow, which reduced both microbial proliferation and the production of proteins and polysaccharides in the cake layer and contributed significantly to improving the overall ultrafiltration performance. $\mathrm{NaClO}$ dosing had no adverse impact on the formation of currently regulated disinfection by-product compounds (THMs and HAAs).

M embrane fouling remains a major barrier limiting the application of ultrafiltration in water and wastewater treatment owing to the resulting increased operating costs and operational constraints (e.g. lower membrane fluxes). Various factors affect membrane fouling, including the membrane characteristics, water conditions, the type of pre-treatment (choice of coagulant and dose), and the operating conditions ${ }^{1}$, but not the mixed liquor suspended solids concentration or zeta potential of biomass in the case of membrane bioreactors $(\mathrm{MBRs})^{2}$. Tian et al. ${ }^{3}$ found that the biopolymer content in water is an important indicator for predicting membrane fouling potential in UF processes, and there was no correlation with the presence of humic substances and UF membrane fouling.

Floc-bound extracellular polymeric substances (EPS) have been suggested to play a role in the fouling process of full-scale and the pilot-scale MBR units ${ }^{4}$. Also, it has been reported that proteins and polysaccharides could be the cause of biofouling ${ }^{5}$. During the long-term operation of an MBR, bound EPS demonstrated positive correlations with membrane fouling ${ }^{6}$, produced by different species of bacteria ${ }^{7}$. Other studies have reported that the concentration of soluble EPS or polysaccharides, and the number and size of the bioflocs were responsible for the observed differences in the membrane fouling ${ }^{8,9}$.

It has been shown that the increased adsorption of EPS onto a membrane resulted in a significant decrease in permeate water flux, and EPS production may influence sludge deposition (and attachment rate) and thereby affect the biofouling propensity of the membrane ${ }^{10}$. The aggregation abilities of sludge samples have been shown to decrease with the extraction of EPS, which confirmed the crucial role of EPS in sludge aggregation, including loosely bound EPS and tightly bound EPS ${ }^{11}$. It has also been observed that the accumulation of biopolymer clusters in the sludge mixture of a MBR facilitates the formation of a sludge fouling layer on the membrane surface, thus causing serious fouling ${ }^{12}$. Furthermore, as the thickness of the bio-cake grows, an anoxic and endogenous environment may develop in the lower parts of the bio-cake layer, ultimately leading to cell lysis and release of polysaccharides ${ }^{13,14}$.

In view of the foregoing observations it is evident that decreasing the EPS concentration and/or inactivating bacteria on the surface of a membrane are potential methods of mitigating fouling. Various approaches have been studied and reported in the literature. A quorum quenching enzyme (acylase) was directly immobilized onto a nanofiltration membrane to mitigate biofouling in a nanofiltration process, which prohibited the formation of a mushroom-shaped mature biofilm ${ }^{15}$. Fungal inoculation was found to prevent biofouling of MBRs by microbial degradation of primary biofoulants ${ }^{16}$. Modification of the membrane surface to provide anti-adhesion and antibacteria properties has been studied ${ }^{17}$, as well as grafting copolymers on PVDF surfaces to provide a potent anti- 
Table 1 | Water quality of raw water and UF influents*/filtrates

\begin{tabular}{lccccc} 
Parameter** & Raw water & CUF influent & CUF-Cl influent & CUF filtrate & CUF-Cl filtrate \\
\hline $\mathrm{UV}_{254}\left(\mathrm{~cm}^{-1}\right)$ & $0.106 \pm 0.006$ & $0.037 \pm 0.002$ & $0.039 \pm 0.002$ & $0.034 \pm 0.003$ & $0.035 \pm 0.002$ \\
$\mathrm{TOC}(\mathrm{mg} / \mathrm{L})$ & $4.795 \pm 0.415$ & $3.382 \pm 0.185$ & $3.541 \pm 0.302$ & $1.985 \pm 0.234$ & $2.490 \pm 0.287$ \\
Turbidity(NTU) & $2.95 \pm 0.16$ & $2.50 \pm 0.28$ & $2.43 \pm 0.35$ & $0.02 \pm 0.02$ & $0.03 \pm 0.03$ \\
$\mathrm{Al}(\mathrm{mg} / \mathrm{L})$ & $0.050 \pm 0.006$ & $0.059 \pm 0.004$ & $0.065 \pm 0.003$ & $0.053 \pm 0.008$ & $0.061 \pm 0.003$ \\
$\mathrm{P}(\mathrm{mg} / \mathrm{L})$ & $0.250 \pm 0.035$ & $0.009 \pm 0.002$ & $0.027 \pm 0.008$ & $0.011 \pm 0.002$ & $0.014 \pm 0.005$ \\
$\mathrm{NO}_{3}^{-}-\mathrm{N}(\mathrm{mg} / \mathrm{L})$ & $4.89 \pm 1.31$ & $6.82 \pm 0.49$ & $5.97 \pm 0.55$ & $7.23 \pm 0.27$ \\
$\mathrm{NH}_{4}^{+}-\mathrm{N}(\mathrm{mg} / \mathrm{L})$ & $1.62 \pm 0.45$ & $0.21 \pm 0.12$ & $0.56 \pm 0.23$ & $0.11 \pm 0.06$ & $0.29 \pm 0.13$ \\
$\mathrm{Active} \mathrm{Cl}(\mathrm{mg} / \mathrm{L})$ & $0.10 \pm 0.02$ & $0.08 \pm 0.02$ & $0.31 \pm 0.08$ & $0.06 \pm 0.02$ & $0.23 \pm 0.05$ \\
$\mathrm{pH}$ & $7.85 \pm 0.06$ & $7.37 \pm 0.04$ & $7.36 \pm 0.04$ & $7.40 \pm 0.05$ & $7.42 \pm 0.03$ \\
\hline
\end{tabular}

*Influent - within membrane tank, immediately after flocculation units

**For turbidity, $\mathrm{UV}_{254}$, and DOC, the number of measurements, $\mathrm{n}=9$; for residual $\mathrm{Al}, \mathrm{P}, \mathrm{NO}_{3}{ }^{-}-\mathrm{N}^{-}$and $\mathrm{NH}_{4}{ }^{+}-\mathrm{N}, \mathrm{n}=5$.

biofouling behavior ${ }^{18}$. Coating $\mathrm{TiO}_{2} /$ polyvinyl alcohol (PVA) on the membrane surface could loosen the cake layer and decrease filtration resistance (membrane fouling) in the treatment of a simulated wastewater ${ }^{19}$. We believe some of the more extensive research on MBR processes is relevant to the drinking water application.

In addition to changing the surface properties of the membrane, other studies have found that many factors can be controlled to decrease the membrane fouling, such as mechanical stresses ${ }^{20}$, cell residence times ${ }^{2,21}$, calcium concentration ${ }^{22}$, adding cationic polymeric material ${ }^{23}$ and flocculants ${ }^{24}$, and by applying intermittent direct electrical current ${ }^{25}$. Membrane fouling through fiber clogging that is caused by sludge accumulation on the membrane can be prevented by mechanical methods, such as adding suspended carriers $^{26}$ and moving media ${ }^{27}$. Powdered activated carbon inside the reactor enhanced the biodegradation of polysaccharides and proteins, and mitigated membrane fouling ${ }^{28}$. Membrane fouling could be also effectively prevented by pre-ozonation ${ }^{29,30}$, and both external and internal fouling could be effectively mitigated ${ }^{31}$. A sufficient supply of oxygen could achieve low concentrations of soluble microbial products and reduce membrane fouling ${ }^{9,13,32}$.

Chemical backwashing is also effective for controlling membrane fouling ${ }^{33}$ but represents an additional aspect of the process design and operation. Chlorine treatment (cleaning) is widely used by membrane filtration plants to recover the loss of membrane permeability encountered in low-pressure membrane (LPM) filtration of natural waters $^{34,35}$. Although chemical solutions are widely employed to clean membranes, they can also be responsible for undesirable changes in membrane properties where either the functional properties of the membrane gradually change, or the membrane simply breaks up (hollow fibers) ${ }^{36-38}$; this is a consequence of the need for highly concentrated chemical solutions to wash fouled membranes.

Notwithstanding all the approaches described above for controlling membrane biofouling, the direct application of pre-chlorination has received very little attention to-date. Pre-chlorination is widely applied in treating surface waters for meeting various water quality objectives including pre-disinfection. In this paper, we have evaluated the benefits of applying a low dosage of $\mathrm{NaClO}$ continuously with alum as the pre-treatment before UF membrane filtration, in controlling membrane fouling, which is also confirmed for the surface water treatment in Beijing in recent days. It has been achieved through laboratory tests involving the quantification of key relevant factors, such as the dead/live ratio of bacteria, extracellular polymeric substances (EPS), and the properties of the cake layer. The experimental study and key findings are described in the following sections.

\section{Methods}

Synthetic raw water and coagulant. A synthetic raw water was prepared for the tests to represent a typical surface water source containing organic pollution arising from land runoff and sewage effluent discharge. Thus, a quantity of domestic settled sewage was added to local (Beijing, China) tap water in a volumetric ratio of $1: 50$, respectively. In addition, $5 \mathrm{mg} / \mathrm{L}$ (TOC $\approx 2 \mathrm{mg} / \mathrm{L}$ ) of humic acid (HA, sodium salt, Aldrich, Cat: H1, 675-2) was added to the raw water. The humic acid and domestic settled sewage represented respectively types of organic matter that are relatively easy or difficult to remove during typical drinking water treatment; the former characterized by high MW (molecular weight) hydrophobic molecules, and the latter low MW hydrophilic substances. Prior to mixing with domestic sewage and humic acid solution, the tap water was left for one night to ensure the complete decay of residual chlorine. The characteristics of the synthetic raw water are listed in Table 1.

Aluminum sulfate hydrate $\left(\mathrm{Al}_{2}\left(\mathrm{SO}_{4}\right)_{3} \cdot 18 \mathrm{H}_{2} \mathrm{O}\right.$; Bodi, China, $\left.>99 \%\right)$ 'alum' was used as a coagulant in this study. Stock alum solution was prepared at a concentration of $0.1 \mathrm{M}$ in DI water. Stock $\mathrm{NaClO}$ was prepared as $1 \mathrm{~g} / \mathrm{L}$ (calculated as active $\mathrm{Cl}$ ) and stored in the dark.

Two pretreatments before UF processes. Traditional coagulation and flocculation by alum without or with addition of $\mathrm{NaClO}$ (at a concentration of $1 \mathrm{mg} / \mathrm{L}$, calculated as active $\mathrm{Cl}$, since higher concentrations of $\mathrm{NaClO}$ may affect or change the membrane properties) before ultrafiltration (referred to as CUF/CUF-Cl) were operated in parallel. A schematic illustration of CUF and CUF-Cl arrangements is shown in Figure S1 in supporting information. Synthetic polluted raw water was fed into a constant-level tank to maintain the water head for the membrane tanks. A certain dose of alum $(0.15 \mathrm{mM})$ with or without $1 \mathrm{mg} / \mathrm{L} \mathrm{NaClO}$ was continuously added into the rapid mixing tanks. The rapid mix speed was $200 \mathrm{rpm}\left(\mathrm{G}=184 \mathrm{~s}^{-1}\right.$; calculated as our previous work ${ }^{39}$ ) in the mixing tank with a hydraulic retention time (HRT) of $1 \mathrm{~min}$, which then reduced to $50 \mathrm{rpm}\left(23 \mathrm{~s}^{-1}\right)$ in the three flocculation tanks, each having a HRT of $5 \mathrm{~min}$. After the flocculation tanks, the flow passed directly into the membrane tanks. Each tank contained a submerged polyvinylidene fluoride (PVDF) hollow-fiber UF membrane module (Tianjin Motimo Membrane Technology Co., Ltd, China) with a nominal pore size of $0.03 \mu \mathrm{m}$ and a surface area of $0.025 \mathrm{~m}^{2}$. The permeate through the submerged membrane module was continuously withdrawn using a peristaltic pump at a constant flux of $20 \mathrm{~L} \cdot \mathrm{m}^{-2} \cdot \mathrm{h}^{-1}$, operated in a cycle of $30 \mathrm{~min}$ filtration and $1 \mathrm{~min}$ backwash $\left(40 \mathrm{~L} \cdot \mathrm{m}^{-2} \cdot \mathrm{h}^{-1}\right)$. Air was supplied to each reactor at $100 \mathrm{~L} / \mathrm{h}$ (air: water $=200: 1$ ) only at every backwash. The transmembrane pressure (TMP) was continuously monitored with pressure gauges. The HRT of the membrane tanks was maintained at $0.5 \mathrm{~h}$ and accumulated sludge was released every 2 days. The ultrafiltration process lasted for more than 60 days, and the cake layer on the surface of membrane was removed by high pressure tap water washing once for the CUF system over the whole operation process. The operation conditions can be found in Table S1 of the supporting information.

Flow-cytometric measurements for bacteria in membrane tanks. The variation of bacteria in the membrane systems was measured by flow cytometry. Before staining and measurement, water samples were filtered by copper mesh (300 meshes), and then EDTA was added to all samples immediately before staining to disrupt the outer membrane of Gram-negative bacteria in water ${ }^{40}$.

Before analysis, all samples were incubated in the dark at $20^{\circ} \mathrm{C}$ for $25 \mathrm{~min}$ and then stained with a mixture of SYBR ${ }^{\circledR}$ Green I and propidium iodide (PI); staining concentrations were those reported previously ${ }^{41}$. Live cells have intact membranes and are impermeable to dye PI, which only leaks into cells with compromised membranes. SYBR ${ }^{\circledR}$ Green I stains all bacterial cells irrespective of their physiological state and stained cells can easily be distinguished from instrument background with flow cytometry. Thus a combination of these two dyes provides a rapid and reliable method for discriminating live and dead bacteria. Flow-cytometric measurements were made with a Partec CyFlow Space flow cytometer (BD Biosciences, San Jose, CA) with $488 \mathrm{~nm}$ excitation from a blue solid-state laser at $200 \mathrm{~mW}$. In the flow cytometer, optical filters were set up so that PI was measured above $630 \mathrm{~nm}$ and SYBR ${ }^{\circledR}$ Green I, at $520 \mathrm{~nm}^{41}$.

Extraction and measurements of EPS from cake layer and sludge. At the end of operation, the fouled membrane modules were taken out from the reactors. The external foulants on the membrane surface were carefully scraped off with a plastic sheet (Deli, China). A heating and extraction method $^{42}$ was modified to extract the loosely bound EPS (LB-EPS) and tightly bound EPS (TB-EPS) from the cake layers, and make sure the EPS was not released from bacterial cells. Sludge suspension from cake layers was first dewatered by centrifugation (Anke TGL-10B, China) in a 20-mL tube at $4000 \mathrm{~g}$ for $5 \mathrm{~min}$. The concentrate liquor was recovered for water quality 

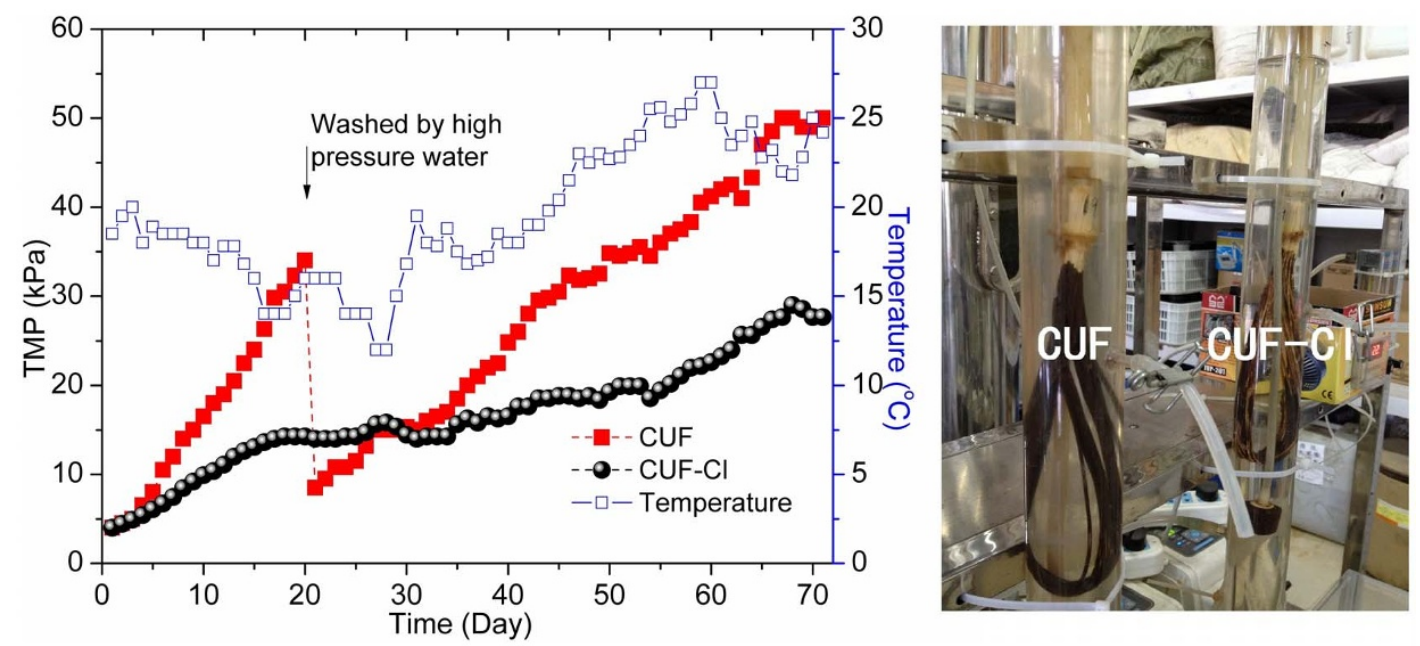

Figure 1 | Variation of TMP with time for different pretreatment conditions over an operating period of approximately 70 days $\left(20 \mathrm{~L} . \mathrm{m}^{-2} \cdot \mathrm{h}^{-1}\right)$.

analysis. The sludge pellet in the tube was re-suspended in $10 \mathrm{~mL}$ phosphate buffer saline (PBS) solution, and the sludge suspension was then ultrasonically treated (KH250DE, KunShanHeChuangultrasonic Co., Ltd., China) for $2 \mathrm{~min}$. Without any delay, the suspension was then sheared by a vortex mixer (Vortex- Genie ${ }^{\circledR}$ 2, Mo Bio laboratories, Inc., USA) for $15 \mathrm{~min}$, followed by centrifugation at $4000 \mathrm{~g}$ for $10 \mathrm{~min}$. The organic matter in the supernatant was readily extractable EPS, and was regarded as the LB-EPS of the biomass. For extracting the TB-EPS, the sludge pellet left in the centrifuge tube was re-suspended in PBS solution to its original volume $(10 \mathrm{~mL})$, ultrasonically treated for $3 \mathrm{~min}$, and heated to $80^{\circ} \mathrm{C}$ in a water bath for $30 \mathrm{~min}$. The mixture was centrifuged at $20000 \mathrm{~g}$ for $15 \mathrm{~min}$. The supernatant collected was regarded as the TB-EPS.

EPS extracted from the cake layer and sludge was measured by three-dimensional excitation-emission matrix (EEM) fluorescence and size exclusion chromatography (SEC). EEM fluorescence measurements were conducted using a spectrofluorometer (FP-6500, Jasco, Japan) equipped with a $150 \mathrm{~W}$ xenon lamp at ambient temperature of $25^{\circ} \mathrm{C}$. Further details of the method can be found in previous research reported elsewhere ${ }^{31,43}$. SEC was carried out to determine the apparent molecular weight (MW) distribution of UV-active substances of EPS extracted from the cake layer and sludge.
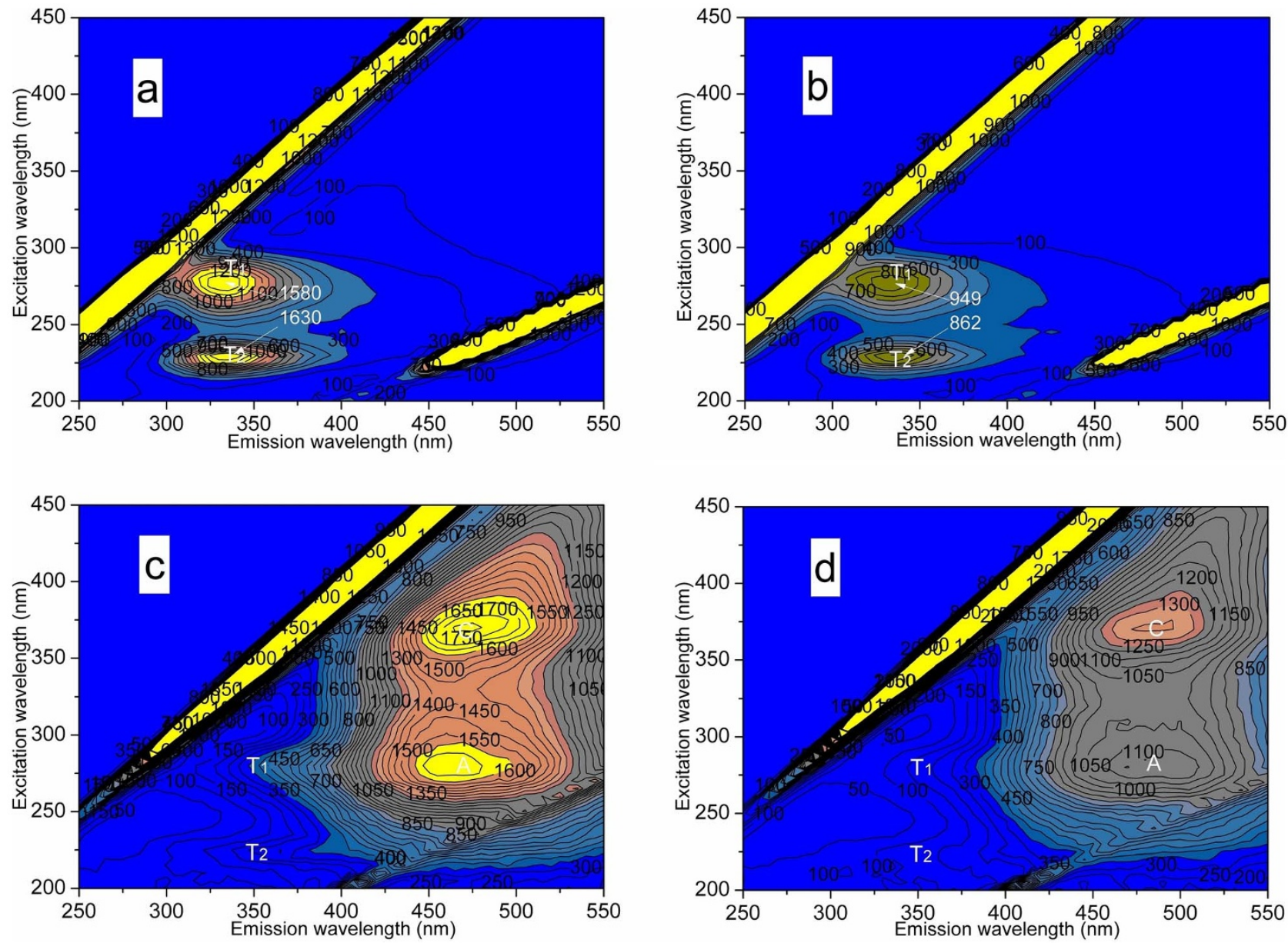

Figure $2 \mid$ EEM fluorescence spectra of EPS in cake layer on the membrane surface: LB-EPS on CUF (a) and CUF-Cl (b), TB-EPS on CUF (c) and CUF$\mathrm{Cl}$ (d). 

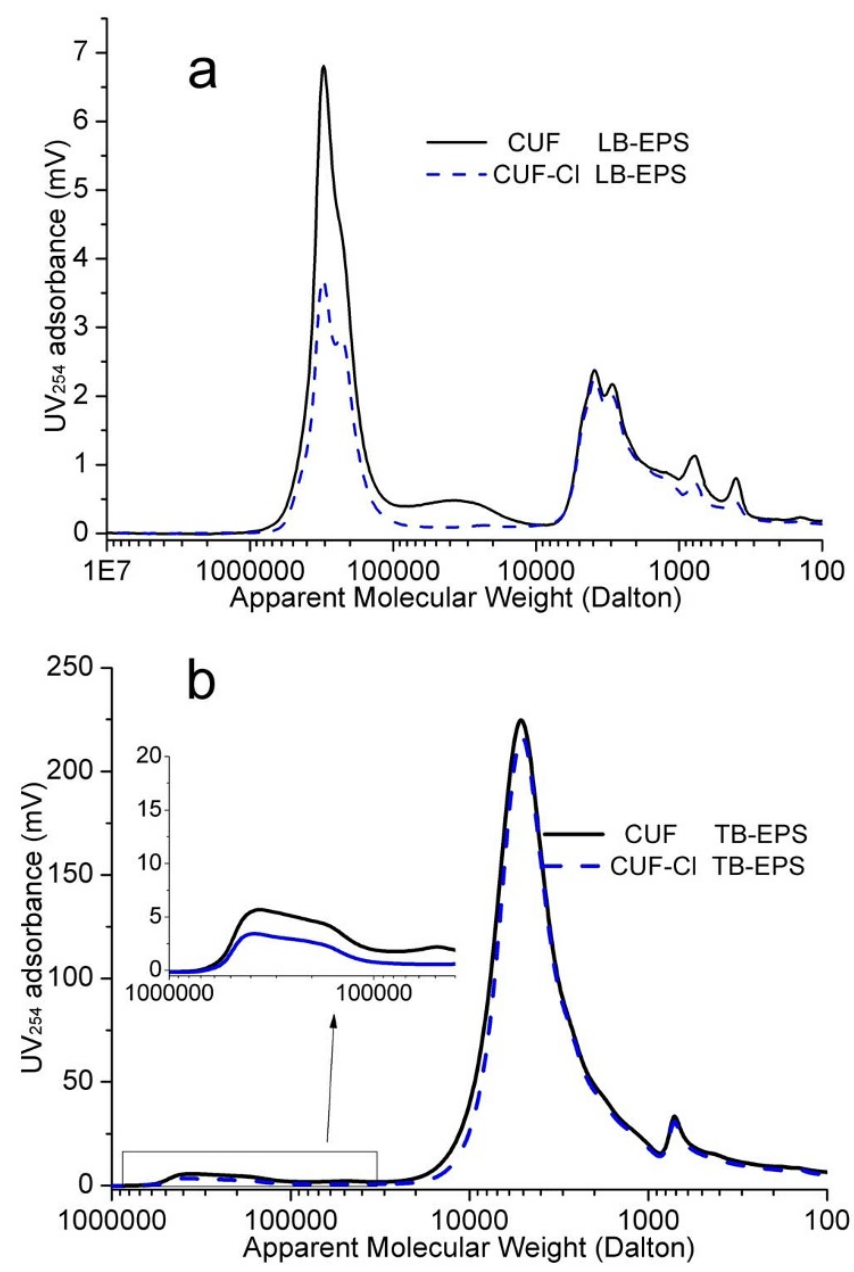

Figure 3 MW distribution of EPS from cake layer and different ages of sludge: LB-EPS (a) and TB-EPS (b) (same conditions as for Figure 2 and Figure S2).

This measurement procedure was adapted from the method described by Allpike et al. ${ }^{44}$.

Fluorescence staining and confocal laser scanning microscopy (CLSM). Intact, living, and hydrated granules and flocs were stained with fluorescently labeled probes with different excitation and emission spectra in order to visualize the distribution of cells, polysaccharides, and proteins in samples. Samples were stained in $1.5-\mathrm{ml}$ Eppendorf tubes, covered with aluminum foil, and placed on a shaker table (100 rpm) for $15 \mathrm{~min}$ each. After being stained by three dyes separately, whole samples were visualized directly by confocal laser scanning microscopy (CLSM; TCS SP 5, Leica, Germany). The probes were visualized on three channels with corresponding excitation and emission wavelengths as follows: FITC (488 nm/520 nm), ConA $(543 \mathrm{~nm} / 560 \mathrm{~nm})$, and DAPI $(371 \mathrm{~nm} / 397 \mathrm{~nm})$.

Fluoresceinisothiocyanate (FITC) $(0.01 \%)$ is an amine reactive dye and stains all proteins and amino-sugars of cells and $\mathrm{EPS}^{45}$. Concanavalin A (ConA) lectin conjugated with Texas Red $(100 \mu \mathrm{g} / \mathrm{ml})$ was used in the present study to bind to $\alpha$-mannopyranosyl and $\alpha$-glucopyranosyl sugar residues. DAPI is a cell-permeative nucleic acid stain and was used to visualize all cells. All probes were purchased from Molecular Probes (U.S.A.), and samples were washed with PBS after each staining step.

Scanning electron microscopy (SEM) images. The fouled membrane fibers were cut from the two membrane modules, and the foulant layer was retained on the membrane surface. The new and fouled membrane samples were then platinumcoated by a sputter and observed under scanning electron microscopy (SEM; JSM7401F, JEDL, Japan).

\section{Results}

TMP development in CUF and CUF-Cl systems. The addition of $\mathrm{NaClO}$ together with pre-coagulation by alum before ultrafiltration (CUF-Cl) was compared to only pre-coagulation by alum (CUF). In
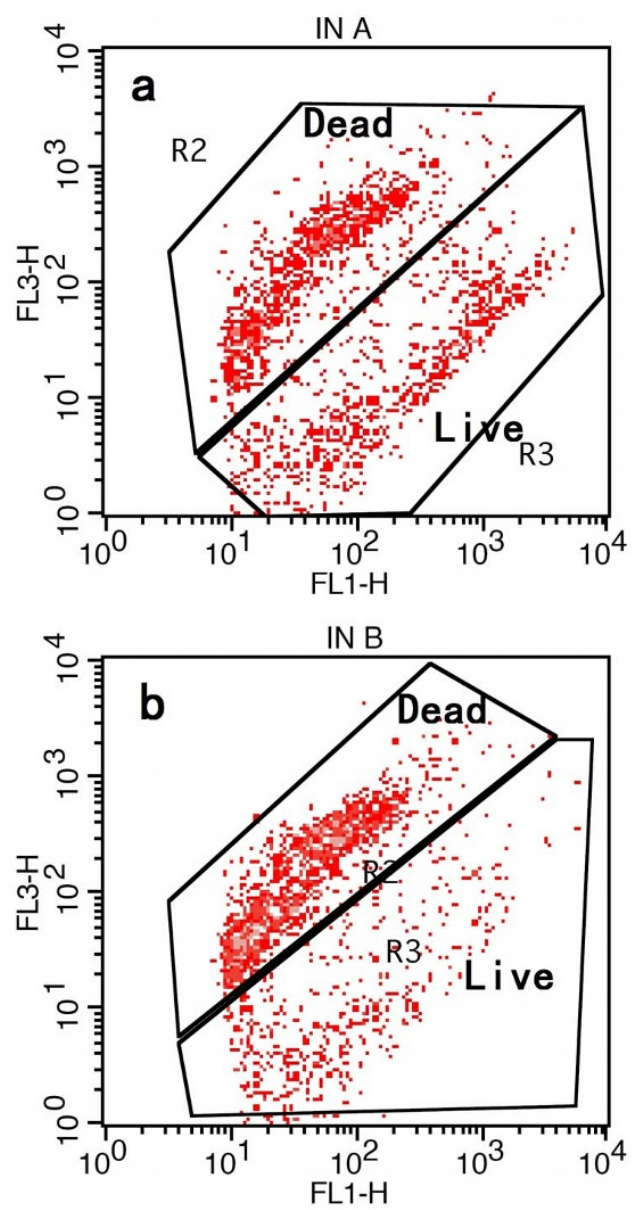

Figure $4 \mid$ Examples of flow-cytometric dot plots from stained water samples: a) CUF influent and b) CUF-Cl influent.

these experiments, the membrane flux of the CUF and CUF-Cl streams were both set at a constant value of $20 \mathrm{~L} \cdot \mathrm{m}^{-2} \cdot \mathrm{h}^{-1}$ in a cycle of $30 \mathrm{~min}$ filtration/1 min water backwash, and membrane fouling was represented by the increase in TMP. The comparative increase in TMP for the CUF and CUF-Cl streams is shown in Figure 1. It can be seen that the TMP in both membrane tanks increased with time from an initial value of $4.5 \mathrm{kPa}$, and that a high pressure water wash was required for the CUF membrane on the $20^{\text {th }}$ day, but none was required for the CUF-Cl membrane throughout the 70 day run.

Comparing the two types of pretreatment, it was clear that the membrane fouling was dramatically different. The combination of alum and $\mathrm{NaClO}$ produced a membrane fouling rate much lower than that of only alum (Figure 1). The slope/gradient of the TMP increase with time (TMP rate) can be used to indicate the fouling rates $^{46,47}$. The TMP increased quickly to $35 \mathrm{kPa}$ from $4.5 \mathrm{kPa}$ after 20 days' operation in the CUF system (TMP rate approximately $1.5 \mathrm{kPa}$ /day), but it only increased to $12 \mathrm{kPa}$ in the CUF-Cl system (TMP rate approximately $0.38 \mathrm{kPa} /$ day). After 20 days of operation, the membrane module in the CUF was taken out from the tank and cleaned by high pressure tap water. It can be seen that the TMP of CUF membrane after washing was $8 \mathrm{kPa}$, which was only slightly higher than that of a new membrane. Therefore, we can conclude that the membrane fouling was mainly determined by the cake layer on the membrane surface.

The TMP of the CUF membrane after the high pressure wash increased substantially during the subsequent period of continuous operation, and reached a value of nearly $50 \mathrm{kPa}$ after approximately 50 days (TMP rate approximately $1.0 \mathrm{kPa}$ /day). The lower TMP rate after washing, compared to the rate before, was believed to be because 

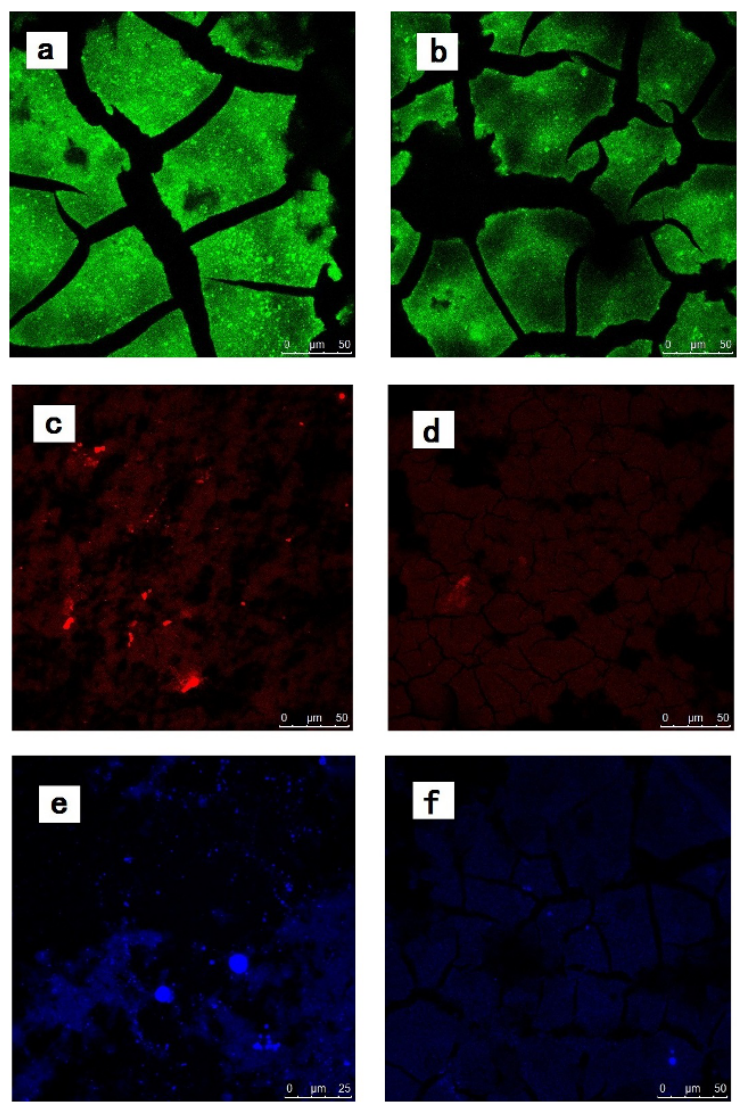

Figure $5 \mid$ CLSM images of cake layer on the surface of membranes: stained with FITC in CUF (a) and CUF-Cl (b), stained with ConA-Red in CUF (c) and CUF-Cl (d), and stained with DAPI in CUF (e) and CUF-Cl (f) (FITC stains all proteins and amino-sugars of cells and EPS; ConATexas Red stains $\boldsymbol{\alpha}$-mannopyranosyl and $\boldsymbol{\alpha}$-glucopyranosyl sugar residues; DAPI stains all dead and live cells).

of the increase in water temperature and variation of water quantity. In sharp contrast, a much lower TMP rate (around $0.2 \mathrm{kPa}$ /day) was evident in the CUF-Cl system throughout the whole period of operation. It was apparent that the TMP became relative stable from the $18^{\text {th }}$ day to the $50^{\text {th }}$ day, and then gradually increased to $27 \mathrm{kPa}$ at the $72^{\text {th }}$ day.

The photograph in Figure 1 shows visually different cake layers on the surface of CUF and CUF-Cl membranes at the $60^{\text {th }}$ day's operation, where the much thinner cake layer on the surface of CUF-Cl membrane (also see section 3.7) corresponded well with the lower rate of TMP increase.

Comparison of EPS by EEM in the two membrane systems. Many researchers have found that membrane filtration performance was determined by the EPS in the cake layer for waste water treatment (e.g. Laabs et $\mathrm{al}^{48}$ ). Therefore, in this study, the EPS was extracted from the cake layer and sludge from this synthetic drinking water, and then analyzed using EEM spectroscopy at the end of operation with respect to LB-EPS and TB-EPS (Figure 2).

Information describing the nature of peaks within EEM fluorescence spectra has been reported by some researchers ${ }^{31,43}$. The results here showed that LB-EPS was mainly composed of proteinlike substances (intensity peak $\mathrm{T}_{1}$ and peak $\mathrm{T}_{2}$ ), but its concentration in the cake layer from the two membrane systems was significantly different (Figures $2 \mathrm{a}$ and $2 \mathrm{~b}$ ). Peak $\mathrm{T}_{1}$ and peak $\mathrm{T}_{2}$ in the CUF tank were higher than in the CUF-Cl tank, which indicated that some bacteria were inactivated by the presence of $\mathrm{NaClO}$ and produced less LB-EPS.
The EEM fluorescence spectra of TB-EPS extracted from the cake layers in the CUF and CUF-Cl systems are shown in Figure 2 (c and d). It was demonstrated that TB-EPS were composed of humic-like substances represented by Peak A and peak C, as the primary components in the cake layer of the two systems. The appearance of dominant humic acid-like peaks of TB-EPS extracted from the cake layer in both systems indicated the accumulation of humic acid-like substances on the membrane surface. The intensities of peak A and peak $\mathrm{C}$ in the CUF cake layer were much higher than in the CUF-Cl. Although peak A overlapped peaks $\mathrm{T}_{1}$ and $\mathrm{T}_{2}$, both two peaks can be distinguished, which showed that there were still some protein-like materials in TB-EPS. It was evident that the intensities (fluorescence units - FU) of peak $\mathrm{T}_{1}(358 \mathrm{FU})$ and peak $\mathrm{T}_{2}(258 \mathrm{FU})$ in the CUF cake layer were greater than those in the CUF-Cl system (165 and 126 $\mathrm{FU}$, for peak $\mathrm{T}_{1}$ and $\mathrm{T}_{2}$ ).

Overall, the higher LB-EPS and TB-EPS concentrations observed in the CUF cake layer, than in the CUF-Cl cake layer, may be one of the main reasons for the different degree of membrane fouling in the two systems.

Comparison of EPS by SEC in the two membrane systems. The apparent MW distributions of LB-EPS and TB-EPS extracted from the cake layers in the CUF and CUF-Cl systems were measured by SEC and given in terms of UV absorbance at $254 \mathrm{~nm}$ (Figure 3). There were two main peaks with MW between $10^{5}$ and $10^{6}$ (EPS), and between $10^{3}$ and $10^{4}$ (HA) for both LB-EPS and TB-EPS. The higher MW peak $\left(>10^{5}\right)$ is most likely attributable to polysaccharide and protein-like substances, which was reported previously by AlHalbouni et al. ${ }^{49}$.

Comparing the LB-EPS substances extracted from the two cake layers, there appeared to be no significant differences in the absorbance peak in the range, $10^{3} \sim 10^{4}$. In contrast, for the MW peak between $10^{5}$ and $10^{6}$, the magnitude of the absorbance was significantly greater, and the concentration of LB-EPS extracted from the CUF cake layer was much greater than from the CUF-Cl cake layer. The difference in MW distributions of LB-EPS in the cake layers in the CUF and CUF-Cl systems suggested that fewer bacteria in the CUF-Cl system produced less LB-EPS, which may influence the nature of the cake layer.

For TB-EPS, it was found that the dominant organic matter were HA-type substances with MW between $10^{3}$ and $10^{4}$, but there were no significant differences in the MW distributions for the cake layers in the CUF and CUF-Cl systems. Comparing Figure $3 \mathrm{~b}$ with Figure 2, it is evident that peaks $\mathrm{A}$ and $\mathrm{C}$ in the EEM spectra were not only composed of HA substances, since a secondary peak was present in the MW range of $10^{5}$ and $10^{6}$. The concentration of organic matter with MW between $10^{5}$ and $10^{6}$ in the CUF cake layer was greater than that in the CUF-Cl cake layer. In the light of these results, it seems that controlling the concentration of LB-EPS may be a good way to decrease the membrane fouling.

Variation of bacteria measured by flow cytometry. As living bacteria in the membrane system produce EPS, which may contribute to membrane fouling, measurements of the ratio of dead/live bacteria in the influent of both membrane systems were made using flow cytometry with staining by a combination of SYBR ${ }^{\circledR}$ Green I and PI. Two clusters, representing dead and live fractions, were observed for both membrane systems, as shown in Figure 4, and the dead/live ratio was $38.4 \% / 61.6 \%$ in the CUF influent. For the CUF-Cl influent, a shift of the two clusters increased the red fluorescence intensity in the dead cell part, and the dead/live ratio was $72.2 \% / 25.8 \%$. These measurements are consistent with the expected inactivation of bacteria in the UF influent caused by the addition of $\mathrm{NaClO}$. In addition, it was evident from Table 1 that the concentration of $\mathrm{NH}_{4}{ }^{+}-\mathrm{N}$ in the CUF-Cl influent (tank) was higher than in the CUF influent (tank), which indicated there was less overall nitrification $\left(\mathrm{NH}_{4}{ }^{+}-\mathrm{N}\right.$ into $\left.\mathrm{NO}_{3}{ }^{-}-\mathrm{N}\right)$ in the CUF-Cl 

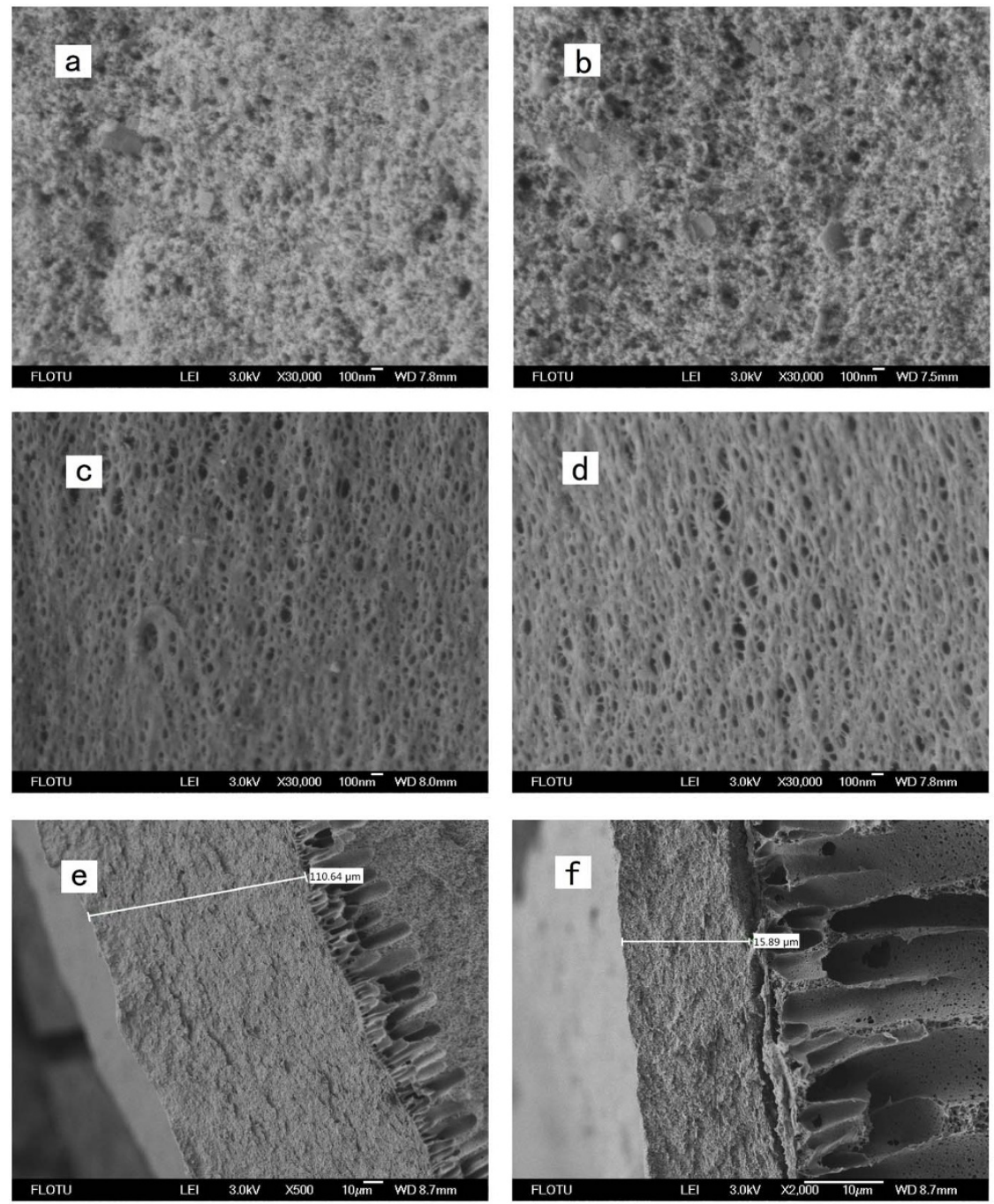

Figure 6 SEM images of membranes with different pretreatments: membrane fouled by CUF flocs (a) and CUF-Cl flocs (b); fouled membrane surface washed by DI water in the CUF (c) and CUF-Cl (d) systems; cross-section of CUF cake layer (e) and CUF-Cl cake layer (f).

system owing to inactivation of bacteria by $\mathrm{NaClO}$. The presence of bacterial populations with different dead/live ratios in the cake layer on the membrane surface may produce different EPS (protein and polysaccharide) concentrations in the cake layer. Thus, for the CUF$\mathrm{Cl}$ system a lower EPS produced by the higher dead/live ratio of bacteria, may induce a lower connection ability of flocs onto the cake layer, and thereby contribute to a lower degree of membrane fouling, as the existence of EPS increases the aggregation abilities of sludge/floc ${ }^{11}$.

CLSM. In order to further confirm the higher concentrations of protein, polysaccharides and bacteria in the CUF than in the CUF$\mathrm{Cl}$ systems, CLSM images of samples of the cake layer were taken. It was found that protein and polysaccharides (sugar) were extensively distributed on both membrane surfaces, together with some bacteria (Figure 5). Comparing the two cake layers, it was evident that more proteins and polysaccharides (sugar) were present in the CUF cake layer than in the CUF-Cl cake layer (Figures 5a-5d). Similarly, the DAPI stain images indicated a higher concentration of bacteria in the CUF cake layer (Figures $5 \mathrm{e}$ and 5f). More than 10 images for every sample confirmed these results, which were of statistic.

The images showed that the addition of $\mathrm{NaClO}$ inactivated bacterial activity in the CUF-Cl system, leading to lower concentrations of bacteria, and their associated proteins and polysaccharides, in the cake layer. Since polysaccharides and proteins can enhance the connection ability of flocs within the cake layer, their lower concentrations in the CUF-Cl system contributed to a reduced thickness of the cake layer. The evidence from these CLSM images is consistent with the other tests described above with regard to the relative presence of bacterial populations and the impact on TMP in the two systems.

SEM images. The tests described above have focused on microbial indicators, but did not consider the structure of the membrane cake layer. Figure 6 presents SEM images of fouled and washed UF membranes and cross-section images of the cake layer. The precoagulated fouling layer looked like a colloidal deposit with relatively low density, which was formed by small primary particles of around $30 \mathrm{~nm}$ size (Figure 6a). According to the SEM images of the cake layer on the surface of membrane, although the size of the nano-scale primary particles changed little by the addition of $\mathrm{NaClO}$, the porosity of the cake layer in the CUF-Cl system appeared to be greater than in the CUF system. Comparing the images of the fouled membranes after washing by sponge, the porosity of both membranes was very similar (Figures $6 \mathrm{c}$ and $6 \mathrm{~d}$ ), but had decreased slightly, compared to a new membrane (Figure S2), through particulate adsorption in/on the membrane pores/ surface. These results indicate that the addition of $\mathrm{NaClO}$ increased the porosity of the cake layer, but did not change the extent of internal membrane fouling. 
SEM images were also used to provide information about the thickness of the cake layer on the surface of the two membranes (Figures 6e and 6f); this was based on samples cut from the top of the membrane modules. The cake layer formed in the CUF system was considerably thicker than in the CUF-Cl system (more than 6 times). It is believed that the high concentration of proteins and polysaccharides (especially LB-EPS) in the CUF cake layer enabled the coagulant flocs or particles to attach easily to the cake layer on the surface of membrane, increasingly with time, thereby forming a thicker cake layer. The results of subsequent research showed that flocs and related nano-particles are difficult to attach onto the surface of bacteria after the addition of $\mathrm{NaClO}$ (Figure S4 in supporting information). Similar results were found with MBR processes in waste water treatment $t^{50,51}$. Therefore, the different pretreatment conditions led to significant differences in the thickness and structure of the cake layers deposited on the membrane surface, thereby causing different degrees of membrane fouling. It is believed that a higher density and larger thickness of the cake layer in the CUF system (external fouling), gave a much higher membrane fouling overall.

Variation of THMs and HAAs in the two membrane tanks. The occurrence and removal of THMs and HAAs in the CUF and CUF$\mathrm{Cl}$ systems were investigated since these compounds were present in the raw water (from the tap water) and formed from the hypochlorite dosing in the CUF-Cl system. The compound concentrations were measured in the raw water, and pre- and post- UF, and the results are shown in Figure S3. As expected, the concentrations of HAAs were generally lower than THMs in the raw and UF influent waters, and influent concentrations were increased slightly by hypochlorite dosing. The combination of coagulation and UF had very little effect on reducing HAA concentrations (Figure S3a) but achieved approximately 50\% reduction in total THMs (Figure S3b). The total THMs was higher in the CUF-Cl influent than in the CUF influent $(60 \pm 10 \mu \mathrm{g} / \mathrm{L}$ and $50 \pm 12 \mu \mathrm{g} / \mathrm{L}$, respectively), but there was no detectable difference after ultrafiltration for the two systems (40 \pm $8 \mu \mathrm{g} / \mathrm{L}$ and $41 \pm 10 \mu \mathrm{g} / \mathrm{L}$ ). In all, a low dosage of $\mathrm{NaClO}$ has no adverse effect on the formation of disinfection by-products.

\section{Conclusions}

1. The combination of alum and a low dose of $\mathrm{NaClO}(1 \mathrm{mg} / \mathrm{l})$ as pretreatment before UF membrane separation (CUF-Cl) substantially reduced the rate (near $60 \%$ ) of membrane fouling compared to alum only as pretreatment (CUF). The result is also found in drinking water plants (Beijing) by the pilot scale experiments in recent days.

2. The addition of the $\mathrm{NaClO}$ was found to cause a substantial inactivation of bacteria, which resulted in lower microbial proliferation, and less production of proteins and polysaccharides. The lower presence of polysaccharides applied to both loosely-bound (LB-EPS) and tightly-bound (TB-EPS) substances and was evident from a reduction in the concentration of $10^{5}$ to $10^{6} \mathrm{MW}$ compounds. The concentration of polysaccharides within the cake layer is believed to be a key factor causing membrane fouling.

3. Although the size of nano-scale primary particles in the influent flow appeared to be unchanged by the addition of $\mathrm{NaClO}$, the porosity of the cake layer in CUF-Cl system was greater than that without chlorine (CUF system), possibly because of a lower concentration of LB-EPS in the CUF-Cl cake layer. Furthermore, the thickness of the cake layer formed in the CUF-Cl system was substantially thinner (less than 6 times) than that in the CUF system, which is also believed to be the result of lower concentrations of protein and polysaccharide in the cake layer. Thus, the combination of a more porous and thinner cake layer helps to explain the lower rate of membrane fouling as indicated by the TMP.

4. The addition of a low dose of $\mathrm{NaClO}(1 \mathrm{mg} / \mathrm{l})$ did not have any significant adverse effect on the formation of disinfection by-pro- ducts, as indicated by the concentrations of THMs and HAAs after ultrafiltration.

1. Le-Clech, P., Chen, V. \& Fane, T. A. G. Fouling in membrane bioreactors used in wastewater treatment. J Membrane Sci 284, 17-53 (2006).

2. Ng, H. Y., Tan, T. W. \& Ong, S. L. Membrane fouling of submerged membrane bioreactors: Impact of mean cell residence time and the contributing factors. Environ Sci Technol 40, 2706-2713 (2006).

3. Tian, J. Y., Ernst, M., Cui, F. Y. \& Jekel, M. Correlations of relevant membrane foulants with UF membrane fouling in different waters. Water Res 47, 1218-1228 (2013).

4. Al-Halbouni, D., Traber, J., Lyko, S., Wintgens, T., Melin, T., Tacke, D., Janot, A., Dott, W. \& Hollender, J. Correlation of EPS content in activated sludge at different sludge retention times with membrane fouling phenomena. Water Res $\mathbf{4 2}$, 1475-1488 (2008).

5. Haberkamp, J., Ernst, M., Bockelmann, U., Szewzyk, U. \& Jekel, M. Complexity of ultrafiltration membrane fouling caused by macromolecular dissolved organic compounds in secondary effluents. Water Res 42, 3153-3161 (2008).

6. Wang, Z. W., Wu, Z. C. \& Tang, S. J. Extracellular polymeric substances (EPS) properties and their effects on membrane fouling in a submerged membrane bioreactor. Water Res 43, 2504-2512 (2009).

7. Ma, J. X., Wang, Z. W., Yang, Y., Mei, X. J. \& Wu, Z. C. Correlating microbial community structure and composition with aeration intensity in submerged membrane bioreactors by 454 high-throughput pyrosequencing. Water Res 47 , 859-869 (2013).

8. Zhang, J. S., Zhou, J. T., Liu, Y. \& Fane, A. G. A comparison of membrane fouling under constant and variable organic loadings in submerge membrane bioreactors. Water Res 44, 5407-5413 (2010).

9. Hong, S. H., Lee, W. N., Oh, H. S., Yeon, K. M., Hwang, B. K., Lee, C. H., Chang, I. S. \& Lee, S. The effects of intermittent aeration on the characteristics of bio-cake layers in a membrane bioreactor. Environ Sci Technol 41, 6270-6276 (2007).

10. Herzberg, M., Rezene, T. Z., Ziemba, C., Gillor, O. \& Mathee, K. Impact of Higher Alginate Expression on Deposition of Pseudomonas aeruginosa in Radial Stagnation Point Flow and Reverse Osmosis Systems. Environ Sci Technol 43, 7376-7383 (2009).

11. Liu, C. X., Zhang, D. R., He, Y., Zhao, X. S. \& Bai, R. B. Modification of membrane surface for anti-biofouling performance: Effect of anti-adhesion and anti-bacteria approaches. J Membrane Sci 346, 121-130 (2010).

12. Wang, X. M. \& Li, X. Y. Accumulation of biopolymer clusters in a submerged membrane bioreactor and its effect on membrane fouling. Water Res 42, 855-862 (2008).

13. Drews, A., Mante, J., Iversen, V., Vocks, M., Lesjean, B. \& Kraume, M. Impact of ambient conditions on SMP elimination and rejection in MBRs. Water Res 41, 3850-3858 (2007).

14. Hwang, B. K., Lee, W. N., Yeon, K. M., Park, P. K., Lee, C. H., Chang, I. S., Drews, A. \& Kraume, M. Correlating TMP increases with microbial characteristics in the bio-cake on the membrane surface in a membrane bioreactor. Environ Sci Technol 42, 3963-3968 (2008).

15. Kim, J. H., Choi, D. C., Yeon, K. M., Kim, S. R. \& Lee, C. H. Enzyme-Immobilized Nanofiltration Membrane To Mitigate Biofouling Based on Quorum Quenching. Environ Sci Technol 45, 1601-1607 (2011).

16. Okamura, D., Mori, Y., Hashimoto, T. \& Hori, K. Effects of Microbial Degradation of Biofoulants on Microfiltration Membrane Performance in a Membrane Bioreactor. Environ Sci Technol 44, 8644-8648 (2010).

17. Liu, X. M., Sheng, G. P., Luo, H. W., Zhang, F., Yuan, S. J., Xu, J., Zeng, R. J., Wu, J. G. \& Yu, H. Q. Contribution of Extracellular Polymeric Substances (EPS) to the Sludge Aggregation. Environ Sci Technol 44, 4355-4360 (2010).

18. Herzberg, M., Sweity, A., Brami, M., Kaufman, Y., Freger, V., Oron, G., Belfer, S. \& Kasher, R. Surface Properties and Reduced Biofouling of Graft-Copolymers That Possess Oppositely Charged Groups. Biomacromolecules 12, 1169-1177 (2011).

19. Liu, L. F., Zhao, C. Q. \& Yang, F. L. TiO2 and polyvinyl alcohol (PVA) coated polyester filter in bioreactor for wastewater treatment. Water Res 46, 1969-1978 (2012).

20. Menniti, A., Kang, S., Elimelech, M. \& Morgenroth, E. Influence of shear on the production of extracellular polymeric substances in membrane bioreactors. Water Res 43, 4305-4315 (2009).

21. Kimura, K., Naruse, T. \& Watanabe, Y. Changes in characteristics of soluble microbial products in membrane bioreactors associated with different solid retention times: Relation to membrane fouling. Water Res 43, 1033-1039 (2009).

22. Kim, I. S. \& Jang, N. The effect of calcium on the membrane biofouling in the membrane bioreactor (MBR). Water Res 40, 2756-2764 (2006).

23. Hwang, B. K., Lee, W. N., Park, P. K., Lee, C. H. \& Chang, I. S. Effect of membrane fouling reducer on cake structure and membrane permeability in membrane bioreactor. J Membrane Sci 288, 149-156 (2007).

24. Ji, J., Qiu, J. P., Wai, N., Wong, F. S. \& Li, Y. Z. Influence of organic and inorganic flocculants on physical-chemical properties of biomass and membrane-fouling rate. Water Res 44, 1627-1635 (2010).

25. Bani-Melhem, K. \& Elektorowicz, M. Development of a Novel Submerged Membrane Electro-Bioreactor (SMEBR): Performance for Fouling Reduction. Environ Sci Technol 44, 3298-3304 (2010). 
26. Huang, X., Wei, C. H. \& Yu, K. C. Mechanism of membrane fouling control by suspended carriers in a submerged membrane bioreactor. J Membrane Sci 309, 7-16 (2008)

27. Lee, W. N., Kang, I. J. \& Lee, C. H. Factors affecting filtration characteristics in membrane-coupled moving bed biofilm reactor. Water Res 40, 1827-1835 (2006)

28. Khan, M. M. T., Takizawa, S., Lewandowski, Z., Rahman, M. H., Komatsu, K. Nelson, S. E., Kurisu, F., Camper, A. K., Katayama, H. \& Ohgaki, S. Combined effects of EPS and HRT enhanced biofouling on a submerged and hybrid PAC-MF membrane bioreactor. Water Res 47, 747-757 (2013).

29. Kim, J., Davies, S. H. R., Baumann, M. J., Tarabara, V. V. \& Masten, S. J. Effect of ozone dosage and hydrodynamic conditions on the permeate flux in a hybrid ozonation-ceramic ultrafiltration system treating natural waters. J Membrane Sci 311, 165-172 (2008)

30. Van Geluwe, S., Braeken, L. \& Van der Bruggen, B. Ozone oxidation for the alleviation of membrane fouling by natural organic matter: A review. Water Res 45, 3551-3570 (2011).

31. Liu, T., Chen, Z. L., Yu, W. Z. \& You, S. J. Characterization of organic membrane foulants in a submerged membrane bioreactor with pre-ozonation using threedimensional excitation-emission matrix fluorescence spectroscopy. Water Res 45, 2111-2121 (2011).

32. Yun, M. A., Yeon, K. M., Park, J. S., Lee, C. H., Chun, J. \& Lim, D. J. Characterization of biofilm structure and its effect on membrane permeability in MBR for dye wastewater treatment. Water Res 40, 45-52 (2006).

33. Lee, E. J., Kim, K. Y., Lee, Y. S., Nam, J. W., Lee, Y. S., Kim, H. S. \& Jang, A. A study on the high-flux MBR system using PTFE flat sheet membranes with chemical backwashing. Desalination 306, 35-40 (2012).

34. Huang, H., Young, T. A. \& Jacangelo, J. G. Chlorine-induced permeability recovery for low-pressure membrane filtration of natural waters. J Membrane Sci 325, 50-57 (2008)

35. Yoon, H., Baek, Y., Yu, J. \& Yoon, J. Biofouling occurrence process and its control in the forward osmosis. Desalination 325, 30-36 (2013).

36. Rouaix, S., Causserand, C. \& Aimar, P. Experimental study of the effects of hypochlorite on polysulfone membrane properties. J Membrane Sci 277, 137-147 (2006).

37. Arkhangelsky, E., Kuzmenko, D. \& Gitis, V. Impact of chemical cleaning on properties and functioning of polyethersulfone membranes. J Membrane Sci $\mathbf{3 0 5}$, 176-184 (2007).

38. Levitsky, I., Duek, A., Arkhangelsky, E., Pinchev, D., Kadoshian, T., Shetrit, H. Naim, R. \& Gitis, V. Understanding the oxidative cleaning of UF membranes. J Membrane Sci 377, 206-213 (2011).

39. Yu, W. Z., Gregory, J., Yang, Y. L., Sun, M., Liu, T. \& Li, G. B. Effect of Coagulation and Applied Breakage Shear on the Regrowth of Kaolin Flocs. Environ Eng Sci 27, 483-492 (2010).

40. Berney, M., Hammes, F., Bosshard, F., Weilenmann, H. U. \& Egli, T. Assessment and interpretation of bacterial viability by using the LIVE/DEAD BacLight kit in combination with flow cytometry. Appl Environ Microb 73, 3283-3290 (2007).

41. Berney, M., Vital, M., Huelshoff, I., Weilenmann, H. U., Egli, T. \& Hammes, F. Rapid, cultivation-independent assessment of microbialviability in drinking water. Water Res 42, 4010-4018 (2008).

42. Morgan, J. W., Forster, C. F. \& Evison, L. A Comparative-Study of the Nature of Biopolymers Extracted from Anaerobic and Activated Sludges. Water Res 24, 743-750 (1990).

43. Wang, Z. W., Wu, Z. C. \& Tang, S. J. Characterization of dissolved organic matter in a submerged membrane bioreactor by using three-dimensional excitation and emission matrix fluorescence spectroscopy. Water Res 43, 1533-1540 (2009).

44. Allpike, B. P., Heitz, A., Joll, C. A., Kagi, R. I., Abbt-Braun, G., Frimmel, F. H., Brinkmann, T., Her, N. \& Amy, G. Size exclusion chromatography to characterize
DOC removal in drinking water treatment. Environ Sci Technol 39, 2334-2342 (2005).

45. Schmid, M., Thill, A., Purkhold, U., Walcher, M., Bottero, J. Y., Ginestet, P., Nielsen, P. H., Wuertz, S. \& Wagner, M. Characterization of activated sludge flocs by confocal laser scanning microscopy and image analysis. Water Res $\mathbf{3 7}$, 2043-2052 (2003).

46. Le Clech, P., Jefferson, B., Chang, I. S. \& Judd, S. J. Critical flux determination by the flux-step method in a submerged membrane bioreactor. J Membrane Sci 227, 81-93 (2003)

47. Monclus, H., Ferrero, G., Buttiglieri, G., Comas, J. \& Rodriguez-Roda, I. Online monitoring of membrane fouling in submerged MBRs. Desalination 277, 414-419 (2011)

48. Laabs, C. N., Amy, G. L. \& Jekel, M. Understanding the size and character of fouling-causing substances from effluent organic matter (EfOM) in low-pressure membrane filtration. Environ Sci Technol 40, 4495-4499 (2006).

49. Al-Halbouni, D., Dott, W. \& Hollender, J. Occurrence and composition of extracellular lipids and polysaccharides in a full-scale membrane bioreactor. Water Res 43, 97-106 (2009).

50. Tsuneda, S., Aikawa, H., Hayashi, H., Yuasa, A. \& Hirata, A. Extracellular polymeric substances responsible for bacterial adhesion onto solid surface. Fems Microbiol Lett 223, 287-292 (2003).

51. Sweity, A., Ying, W., Ali-Shtaye, M. S., Yang, F., Bick, A., Oron, G. \& Herzberg, M. Relation between EPS adherence, viscoelastic properties, and MBR operation: Biofouling study with QCM-D. Water Res 45, 6430-6440 (2011).

\section{Acknowledgments}

This work was supported by National Natural Science Foundation of China (Grants 51290282, 51138008 and 51108444). This research was also supported by a Marie Curie International Incoming Fellowship within the $7^{\text {th }}$ European Community Framework Programme (FP7-PEOPLE-2012-IIF-328867).

\section{Author contributions}

W.Y., N.G. and J.Q. have contributed to the design of the study and the critical revision of the article. W.Y. and X.L. did the experiments, analyzed the data, prepared figures and drafted the article.

\section{Additional information}

Supplementary information accompanies this paper at http://www.nature.com/ scientificreports

Competing financial interests: The authors declare no competing financial interests.

How to cite this article: Yu, W., Xu, L., Graham, N. \& Qu, J. Pre-treatment for ultrafiltration: effect of pre-chlorination on membrane fouling. Sci. Rep. 4, 6513; DOI:10.1038/srep06513 (2014)

This work is licensed under a Creative Commons Attribution-NonCommercialNoDerivs 4.0 International License. The images or other third party material in this article are included in the article's Creative Commons license, unless indicated otherwise in the credit line; if the material is not included under the Creative Commons license, users will need to obtain permission from the license holder in order to reproduce the material. To view a copy of this license, visit http:// creativecommons.org/licenses/by-nc-nd/4.0/ 